\title{
Pemanfaatan Laboratorium (Laboratorium Pusat, Zoologi, Botani) Dalam Perkuliahan Biologi
}

\author{
Evi Apriana ${ }^{1)}$, Anita Noviyanti ${ }^{2)}$, Safriani $^{3)}$, dan Samsul Bahri ${ }^{4)}$ \\ ${ }^{12) 3)}$ Pend. Biologi Universitas Serambi Mekkah Banda Aceh \\ ${ }^{4)}$ MAS Darul Ulum Banda Aceh \\ email: eviapriana@gmail.com
}

\begin{abstract}
Abstrak
Penelitian ini bertujuan untuk mengetahui pemanfaatan laboratorium (laboratorium pusat, zoologi, botani) dan kendala yang dihadapi oleh dosen dan mahasiswa terhadap pemanfaatan laboratorium (laboratorium pusat, zoologi, botani) dalam perkuliahan pada Program Studi Pendidikan Biologi Universitas Serambi Mekkah Banda Aceh. Penelitian ini merupakan penelitian lapangan (field research) yang bersifat kualitatif serta menggunakan pendekatan deskriptif. Sampel dalam penelitian ini adalah dosen (6 orang) dan mahasiswa (25 orang) semester ganjil (masing-masing semester terdapat 5 orang mahasiswa) yang mengikuti perkuliahan biologi. Teknik pengumpulan data adalah angket, wawancara dan observasi. Penelitian dilakukan dengan mengamati dosen, mahasiswa, dan petugas laboratorium yang memanfaatkan laboratorium dalam perkuliahan biologi. Teknik analisis data pada penelitian ini dilakukan secara deskriptif kualitatif. Hasil penelitian menunjukkan bahwa laboratorium pusat, zoologi, botani dapat digunakan untuk melakukan praktikum. Pemanfaatan laboratorium pusat, zoologi, botani dalam perkuliahan biologi telah berjalan dengan baik. Dosen dan mahasiswa saling bekerja sama dalam pemanfaatan fasilitas, alat, bahan, media dan produk yang terdapat di laboratorium tersebut. Kondisi laboratorium pusat, zoologi, botani sangat memadai, adanya petugas laboratorium yang menjaga dan membersihkan peralatan yang ada di laboratorium dengan baik, sehingga mahasiswa dapat melakukan praktikum. Pemanfaatan laboratorium pusat, zoologi, botani adalah untuk praktikum perkuliahan biologi. Hal ini sangat mendukung dan membantu mahasiswa dalam perkuliahan, dengan kedisiplinan dan tanggung jawab dalam memanfaatkan alat dan bahan, agar tidak terjadi kerusakan terhadap alat maupun bahan tersebut. Kendala di laboratorium pusat, zoologi, botani adalah kekurangan alat dan bahan tertentu, pemeliharaan alat dan bahan yang masih kurang, bahkan sangat diperlukan servis perbaikan pada mikroskop yang telah banyak berjamur dan lensanya kurang bersih.

Kata kunci: Pemanfaatan, Laboratorium Pusat, Zoologi, Botani, Perkuliahan Biologi
\end{abstract}

\section{PENDAHULUAN}

Laboratorium adalah tempat belajar mengajar melalui metode praktikum dan demonstrasi yang dapat menghasilkan pengalaman belajar dimana mahasiswa berinteraksi dengan berbagai alat dan bahan untuk mengobservasi gejala-gejala yang dapat diamati secara langsung dan dapat membuktikan sendiri sesuatu yang dipelajari.

Laboratorium (disingkat lab) adalah tempat riset ilmiah, eksperimen, pengukuran ataupun pelatihan ilmiah. Laboratorium biasanya dibuat untuk memungkinkan dilakukannya kegiatan-kegiatan tersebut secara terkendali (Anonim, 2007). 
Laboratorium yang dimanfaatkan oleh dosen dan mahasiswa dalam perkuliahan biologi adalah laboratorium pusat, zoologi dan botani. Dosen mengarahkan mahasiswa dalam melakukan praktek langsung di laboratorium. Laboratorium ini juga memiliki fasilitas, alat dan bahan yang dapat digunakan oleh mahasiswa pada saat melakukan praktikum. Memanfaatkan laboratorium untuk melakukan praktek pembelajaran biologi agar mahasiswa mengetahui dan memahami materi melalui metode praktikum.

Akan tetapi, pada masing-masing laboratorium terdapat kendala dalam pemanfaatannya. Pada laboratorium pusat, jadwal praktikum mahasiswa sangat padat, sehingga proses praktek yang dilakukan mahasiswa sangat terbatas. Sedangkan pada laboratorium zoologi dan botani, mahasiswa tidak dapat melakukan beberapa praktek, dikarenakan pada kedua laboratorium tersebut kekurangan alat dan bahan tertentu.

Dilihat dari fungsinya laboratorium dapat digunakan dengan cara kerja yang teratur dan berlanjut berdasarkan materi bahan ajar bagi mahasiswa. Keberadaan laboratorium ini dapat memicu mahasiswa menjadi lebih tahu. Mereka mendapatkan data dan bukti nyata dari teori yang telah dibaca dan dapat menunjukkan sampai dimana tingkat kemampuan dalam menelaah hasil praktikum sehingga mencapai tujuan perkuliahan yang diharapkan.

Pendidikan biologi menekankan pada pemberian pengalaman belajar secara langsung. Mahasiswa perlu dibantu mengembangkan sejumlah keterampilan proses supaya mereka mampu menjelajahi dan memahami alam sekitar, dan keterampilan mengamati dengan seluruh indera melalui metode praktikum dan demonstrasi di laboratorium. Dengan demikian sangat diperlukan adanya pemanfaatan laboratorium (laboratorium pusat, zoologi, botani) dalam perkuliahan biologi.

\section{METODE PENELITIAN}

Penelitian ini merupakan penelitian lapangan (field research) (Creswell, 2013) yang bersifat kualitatif serta menggunakan pendekatan deskriptif. Penelitian deskriptif ini bermaksud menggambarkan atau melukiskan suatu peristiwa, yaitu mengamati dosen, mahasiswa, dan petugas laboratorium yang memanfaatkan laboratorium dalam perkuliahan biologi. Populasi dalam penelitian ini adalah seluruh mahasiswa, dosen dan petugas laboratorium. Sampel dalam penelitian ini adalah dosen (6 orang) dan mahasiswa (25 orang) semester ganjil (masing-masing semester terdapat 5 orang mahasiswa) yang mengikuti perkuliahan biologi. Teknik pengumpulan data adalah angket, wawancara dan observasi. Teknik analisis data pada penelitian ini dilakukan secara deskriptif kualitatif.

\section{HASIL PENELITIAN DAN PEMBAHASAN}

Hasil penelitian menunjukkan bahwa laboratorium pusat, zoologi, botani dapat digunakan untuk melakukan praktikum. Pemanfaatan laboratorium pusat, zoologi, botani dalam perkuliahan biologi telah berjalan dengan baik.

Hasil angket terhadap dosen menemukan bahwa kondisi laboratorium pusat sudah baik, bersih, dan telah memiliki fasilitas yang lengkap. Laboratorium ini sangat tenang, nyaman, dan tidak ada yang berisik. Laboratorium ini sering dikunjungi oleh mahasiswa untuk melakukan praktikum dan beberapa dosen juga melakukan praktikum dan pengamatan di laboratorium pusat. Mahasiswa lebih banyak melakukan praktikum di laboratorium ini karena alat dan bahan yang memadai, dan mahasiswa menemukan pemahaman konsep karena telah melakukan praktek langsung. Setiap dosen, 
mahasiswa, dan petugas laboratorium diwajibkan menggunakan jas laboratorium yang berwarna putih pada saat masuk dan bekerja di laboratorium pusat.

Laboratorium pusat telah memiliki banyak alat dan bahan yang tersusun rapi pada rak penyimpanan alat dan bahan. Dosen mengarahkan mahasiswa untuk menggunakan alat-alat dengan baik dan benar serta menjaga alat dengan bersih dan rapi. Dosen juga meminta mahasiswa membersihkan alat-alat yang digunakan setelah melakukan praktek biologi. Petugas lab juga mengarahkan agar tidak ada mahasiswa yang membuat hal yang tidak relevan. Selain itu, petugas laboratorium mengawasi alat-alat praktikum yang sedang digunakan oleh mahasiswa. Sangsi yang diberikan berupa penggantian dengan peralatan yang baru. Selain itu juga akan dikenakan denda sesuai dengan kebijakan yang terdapat di peraturan laboratorium.

Bapak/ibu dosen mengawasi mahasiswa pada saat melakukan praktikum di laboratorium selama 2 jam, agar mereka tidak melakukan kesalahan pada saat melakukan praktek dan benar-benar melakukan kegiatan tersebut sesuai dengan arahan. Petugas laboratorium sangat membantu dan mengarahkan mahasiswa menemukan bahan yang dibutuhkan. Petugas lab melakukan berbagai solusi jika tidak menemukan alat-alat dan bahan yang dibutuhkan pada saat melakukan praktek di laboratorium.

Hasil angket terhadap mahasiswa menemukan bahwa keadaan laboratorium pusat tidak ada kendala yang berarti dan kondisinya sangat memadai. Mahasiswa akan masuk lab jika ada pratikum, dan beberapa mata kuliah biologi juga melakukan praktek/kuliah lapangan.

Prodi Pendidikan Biologi memiliki jadwal tersendiri dalam melakukan praktek di laboratorium. Pada saat melakukan praktek di laboratorium, mahasiswa memerlukan waktu selama 2 jam. Dosen membimbing dan mengarahkan mahasiswa pada saat melakukan praktek. Mahasiswa diharuskan menjaga alat dan bahan yang terdapat di laboratorium sehingga tidak rusak dan dapat dimanfaatkan untuk praktikum berikutnya.

Hasil angket dari petugas lab menunjukkan bahwa laboratorium pusat, zoologi dan botani memberikan kesempatan kepada mahasiswa untuk memperoleh banyak informasi dan pengetahuan melalui praktek langsung. Mahasiswa diberikan kesempatan menggunakan alat dan bahan yang terdapat di laboratorium. Akan tetapi, demi menjaga kenyamanan dan keberlangsungan alat-alat yang terdapat di laboratorium, maka petugas lab dan dosen meminta mahasiswa menjaga dengan baik alat-alat yang digunakan dan sebagai sangsinya, mahasiswa harus menggantikan alat-alat yang rusak pada saat digunakan akibat kelalaian.

Pemanfaatan laboratorium dalam proses perkuliahan juga menghadapi kendala. Kendala yang dihadapi oleh dosen dan mahasiswa terhadap pemanfaatan laboratorium pusat, zoologi, botani dalam perkuliahan adalah kedisiplinan dan tanggung jawab dalam memanfaatkan alat dan bahan sehingga terjadi kerusakan terhadap alat dan bahan tersebut.

Hasil observasi menunjukkan bahwa fasilitas, alat, bahan, media pembelajaran, dan produk yang terdapat di laboratorium pusat, botani dan zoologi telah memadai dan dapat digunakan oleh mahasiswa dan dosen dalam melakukan praktikum perkuliahan biologi. Kondisi laboratorium pusat, botani dan zoologi sangat memadai, adanya petugas laboratorium yang menjaga dan membersihkan peralatan yang ada di laboratorium dengan baik, sehingga mahasiswa dapat melakukan praktikum.

Hasil observasi fasilitas di laboratorium pusat, botani dan zoologi dapat dilihat pada tabel 1. berikut ini: 
Tabel 1. Hasil Observasi Fasilitas di Laboratorium Pusat, Botani dan Zoologi

\begin{tabular}{|l|l|c|c|c|}
\hline \multirow{2}{*}{ No } & \multicolumn{1}{|c|}{ Fasilitas } & \multicolumn{2}{c|}{ Pengamatan } & \multirow{2}{*}{ Tidak } \\
\cline { 3 - 4 } & & Ada & $\begin{array}{c}\text { Keterangan } \\
\text { Ada }\end{array}$ & \\
\hline 1 & Lemari penyimpanan alat & $\checkmark$ & & \\
\hline 2 & Lemari penyimpanan bahan & $\checkmark$ & & \\
\hline 3 & Lemari penyimpanan tas mahasiswa & $\checkmark$ & & \\
\hline 4 & Papan tulis & $\checkmark$ & & \\
\hline 5 & Jam dinding & $\checkmark$ & & \\
\hline 6 & Stop kontak & $\checkmark$ & & \\
\hline 7 & Bak cuci & $\checkmark$ & & \\
\hline 8 & Meja samping & $\checkmark$ & & \\
\hline 9 & Meja petugas lab & $\checkmark$ & & \\
\hline 10 & Meja dosen & $\checkmark$ & & \\
\hline 11 & Meja praktikum & $\checkmark$ & & \\
\hline 12 & Kursi petugas lab & $\checkmark$ & & \\
\hline 13 & Kursi dosen & $\checkmark$ & & \\
\hline 14 & Kursi praktikum & $\checkmark$ & & \\
\hline 15 & Kotak P3K & $\checkmark$ & & \\
\hline 16 & Pemadam kebakaran & $\checkmark$ & & \\
\hline 17 & Tabung helium & $\checkmark$ & & \\
\hline 18 & Goni basah & $\checkmark$ & & \\
\hline 19 & Bak pasir & $\checkmark$ & & \\
\hline 20 & Sapu & $\checkmark$ & & \\
\hline 21 & Bulu ayam & $\checkmark$ & & \\
\hline 22 & Kain pel & $\checkmark$ & & \\
\hline 23 & Kain lap & $\checkmark$ & & \\
\hline 24 & Sabun pencuci tangan & $\checkmark$ & & \\
\hline 25 & Jadwal praktikum & $\checkmark$ & \\
\hline 26 & Tata tertib masuk praktikum & $\checkmark$ & \\
\hline 27 & Timba untuk mencairkan zat padat & $\checkmark$ & \\
\hline 28 & Infocus & $\checkmark$ & \\
\hline & Berdasarkan tabel & $\checkmark$ & \\
\hline
\end{tabular}

laboratorium pusat, botani dan zoologi sudah memadai dan dapat digunakan untuk mendukung proses praktikum. Hal ini sangat membantu mahasiswa maupun dosen dalam pelaksanaan perkuliahan biologi dengan metode praktikum dan demonstrasi. Temuan ini senada dengan pernyataan yang dikemukakan oleh Wirjosoemarto, dkk., (2013), bahwa fasilitas laboratorium ada yang berupa fasilitas umum (utilities) dan fasilitas khusus. Fasilitas umum contohnya penerangan, ventilasi, air, bak cuci (sinks), aliran listrik, gas. Fasilitas khusus berupa peralatan dan mebelair, contohnya meja siswa/mahasiswa, meja guru/dosen, meja demonstrasi, meja dinding, kursi, papan tulis, lemari alat, lemari bahan, lemari asam, ruang timbang, perlengkapan P3K, pemadam kebakaran, dll.

Hasil observasi alat yang terdapat di laboratorium pusat adalah sebagai berikut: 
Tabel 2. Hasil Observasi Alat di Laboratorium Pusat

\begin{tabular}{|c|c|c|c|c|c|}
\hline \multirow[b]{2}{*}{ No } & \multirow[b]{2}{*}{ Alat } & \multicolumn{2}{|c|}{ Pengamatan } & \multirow[b]{2}{*}{ Jumlah } & \multirow[b]{2}{*}{ Keterangan } \\
\hline & & Ada & $\begin{array}{c}\text { Tidak } \\
\text { Ada }\end{array}$ & & \\
\hline 1 & Tabung reaksi besar & $\checkmark$ & & 13 buah & \\
\hline 2 & Gelas kimia $600 \mathrm{ml}$ & $\checkmark$ & & 5 buah & \\
\hline 3 & Gelas ukur $250 \mathrm{ml}$ & $\checkmark$ & & 1 buah & \\
\hline 4 & Pipet tetes $10 \mathrm{ml}$ & $\checkmark$ & & 50 buah & \\
\hline 5 & Labu ukur $1000 \mathrm{ml}$ & $\checkmark$ & & 2 buah & \\
\hline 6 & Erlenmeyer $250 \mathrm{ml}$ & $\checkmark$ & & 20 buah & \\
\hline 7 & Pinset & $\checkmark$ & & 6 buah & \\
\hline 8 & Gelas kimia $250 \mathrm{ml}$ & $\checkmark$ & & 14 buah & \\
\hline 9 & Corong & $\checkmark$ & & 12 buah & \\
\hline 10 & Cawan petri plastik & $\checkmark$ & & 14 buah & \\
\hline 11 & Kertas saring & $\checkmark$ & & 2 buah & \\
\hline 12 & Mikroskop & $\checkmark$ & & 20 buah & 1 kurang baik \\
\hline 13 & Sendok & $\checkmark$ & & 5 buah & \\
\hline 14 & Kaca benda & $\checkmark$ & & 2 Set & 5 kurang baik \\
\hline 15 & Thermometer & $\checkmark$ & & 2 set & \\
\hline 16 & Pipet volume $10 \mathrm{~m}$ & $\checkmark$ & & 7 buah & \\
\hline 17 & Lumpang $110 \mathrm{cc}$ & $\checkmark$ & & 5 buah & \\
\hline 18 & Rak tabung reaksi & $\checkmark$ & & 8 buah & \\
\hline 19 & Penjepit tabung & $\checkmark$ & & 16 buah & \\
\hline 20 & Cawan petri kaca & $\checkmark$ & & 27 buah & \\
\hline 21 & Botol reagen besar & $\checkmark$ & & 15 buah & \\
\hline 22 & Botol reagen kecil & $\checkmark$ & & 7 buah & \\
\hline 23 & Jewes's laupe & $\checkmark$ & & 6 buah & \\
\hline 24 & Mikrometer & $\checkmark$ & & 5 buah & \\
\hline 25 & Molyimod & $\checkmark$ & & 1 Set & \\
\hline 26 & Soil tester & $\checkmark$ & & 1 buah & \\
\hline 27 & Timbangan digital & $\checkmark$ & & 1 buah & \\
\hline 28 & Timbangan lengan & $\checkmark$ & & 2 buah & \\
\hline 29 & Cover glass & $\checkmark$ & & 20 pack & \\
\hline 30 & Erlenmeyer $500 \mathrm{ml}$ & $\checkmark$ & & 5 buah & \\
\hline 31 & Erlenmeyer $100 \mathrm{ml}$ & $\checkmark$ & & 8 buah & \\
\hline 32 & Erlenmeyer $50 \mathrm{ml}$ & $\checkmark$ & & 16 buah & 4 kurang baik \\
\hline 33 & Gelas kimia $250 \mathrm{ml}$ & $\checkmark$ & & 15 buah & \\
\hline 34 & Gelas kimia $50 \mathrm{ml}$ & $\checkmark$ & & 25 buah & \\
\hline 35 & Gelas ukur $100 \mathrm{ml}$ & $\checkmark$ & & 13 buah & 3 kurang baik \\
\hline 36 & Gelas ukur $50 \mathrm{ml}$ & $\checkmark$ & & 9 buah & \\
\hline 37 & Gelas ukur $500 \mathrm{ml}$ & $\checkmark$ & & 3 buah & \\
\hline 38 & Gelas ukur $500 \mathrm{ml}$ & $\checkmark$ & & 2 buah & \\
\hline 39 & Gelas ukur $250 \mathrm{ml}$ & $\checkmark$ & & 3 buah & \\
\hline 40 & Kaca arloji & $\checkmark$ & & 1 buah & \\
\hline 41 & Tabung reaksi kecil & $\checkmark$ & & 12 buah & \\
\hline 42 & Tabung respirometer & $\checkmark$ & & 23 buah & \\
\hline 43 & Alu + lumpang & $\checkmark$ & & 1 set & \\
\hline
\end{tabular}




\begin{tabular}{|l|l|c|c|c|l|}
\hline 44 & Batang kaca & $\checkmark$ & & 2 buah & \\
\hline 45 & Batang statif & $\checkmark$ & & 5 buah & \\
\hline 46 & Benang & $\checkmark$ & & 1 buah & \\
\hline 47 & Bola hisap & $\checkmark$ & & 8 buah & \\
\hline 48 & Botol semprot & $\checkmark$ & & 11 buah & \\
\hline 49 & Biuret 50 ml & $\checkmark$ & & 10 buah & \\
\hline 50 & Corong plastik & $\checkmark$ & & 1 buah & \\
\hline 51 & Cawan porselin 100 cc & $\checkmark$ & & 4 buah & \\
\hline 52 & Cawan porselin 50 cc & $\checkmark$ & & 2 buah & \\
\hline 53 & Kaca prima kecil & $\checkmark$ & & 2 buah & \\
\hline 54 & Labu destilasi & $\checkmark$ & & 2 buah & \\
\hline 55 & Lampu spirtus besar & $\checkmark$ & & 10 buah & \\
\hline 56 & Lampu spirtus kecil & $\checkmark$ & & 5 buah & \\
\hline 57 & Kaki tiga & $\checkmark$ & & 3 buah & \\
\hline 58 & Kaca gasa & $\checkmark$ & & 2 buah & \\
\hline 59 & Sikat tabung & $\checkmark$ & & 18 buah & \\
\hline 60 & Spatula kaca & $\checkmark$ & & 8 buah & \\
\hline 61 & Spatula logam & $\checkmark$ & & 10 buah & \\
\hline 62 & Spatula steintis & $\checkmark$ & & 8 buah & \\
\hline
\end{tabular}

Berdasarkan hasil observasi alat di atas, maka dapat diketahui bahwa alat-alat yang terdapat di laboratorium pusat memadai, dalam kondisi baik, dan dapat digunakan dalam proses praktikum. Hanya alat no. 1, 5, 4 dan 3 yang kondisinya tidak baik. berikut:

Hasil observasi bahan yang terdapat di laboratorium pusat adalah sebagai

Tabel 3. Hasil Observasi Bahan di Laboratorium Pusat

\begin{tabular}{|c|c|c|c|c|c|}
\hline \multirow[b]{2}{*}{ No } & \multirow[b]{2}{*}{ Bahan } & \multicolumn{2}{|c|}{ Pengamatan } & \multirow[b]{2}{*}{ Jumlah } & \multirow[b]{2}{*}{ Keterangan } \\
\hline & & Ada & $\begin{array}{c}\text { Tidak } \\
\text { Ada }\end{array}$ & & \\
\hline 1 & Natrium & $\checkmark$ & & 1 botol & \\
\hline 2 & Gelatine & $\checkmark$ & & 1 botol & Rusak \\
\hline 3 & Garam & $\checkmark$ & & 1 botol & \\
\hline 4 & Alkohol & $\checkmark$ & & 2 botol & \\
\hline 5 & Asam asetat & $\checkmark$ & & 1 botol & \\
\hline 6 & Aqudes & $\checkmark$ & & 3 botol & \\
\hline 7 & Amilum & $\checkmark$ & & 1 botol & \\
\hline 8 & Amonium & $\checkmark$ & & 2 botol & \\
\hline 9 & Acetio acid & $\checkmark$ & & 1 botol & \\
\hline 10 & Kalium iodat & $\checkmark$ & & 1 botol & \\
\hline 11 & Glukosa & $\checkmark$ & & 1 botol & \\
\hline 12 & Belerang & $\checkmark$ & & 2 botol & \\
\hline 13 & Benzal dehyde & $\checkmark$ & & 1 botol & \\
\hline 14 & Silver nitrate & $\checkmark$ & & 2 botol & \\
\hline 15 & Sodium carbonat & $\checkmark$ & & 1 botol & \\
\hline 16 & Potassium sulfate & $\checkmark$ & & 1 botol & \\
\hline 17 & Potassium nitrate & $\checkmark$ & & 1 botol & \\
\hline 18 & Acide tartarie & $\checkmark$ & & 1 botol & \\
\hline 19 & aluminium & $\checkmark$ & & 2 botol & \\
\hline
\end{tabular}




\begin{tabular}{|l|l|c|c|c|l|}
\hline 20 & Aluminium sulfate & $\checkmark$ & & 1 botol & \\
\hline 21 & Aluminium chloride & $\checkmark$ & & 1 botol & \\
\hline 22 & Ammonium oksalat & $\checkmark$ & & 1 botol & \\
\hline 23 & Ammonium nitrate & $\checkmark$ & & 1 botol & \\
\hline 24 & Ammonium sulfate & $\checkmark$ & & 2 botol & \\
\hline 25 & Barium hydroxide & $\checkmark$ & & 1 botol & \\
\hline 26 & Barium carbonate & $\checkmark$ & & 3 botol & \\
\hline 27 & Arsenic oxide & $\checkmark$ & & 1 botol & \\
\hline 28 & Ammonium solutien & $\checkmark$ & & 1 botol & \\
\hline 29 & Ammonium carbumatien & $\checkmark$ & & 2 botol & \\
\hline 30 & Magnesium & $\checkmark$ & & 1 botol & \\
\hline
\end{tabular}

Berdasarkan hasil observasi bahan tersebut di atas, maka dapat diketahui bahwa bahan-bahan yang terdapat di laboratorium pusat memadai, dalam kondisi baik, dan dapat digunakan dalam proses praktikum. Hanya 1 bahan yang kondisinya tidak baik atau rusak.

Hasil observasi media pembelajaran yang terdapat di laboratorium pusat juga mendukung pelaksanaan mata kuliah praktek, yaitu:

Tabel 4. Hasil Observasi Media Pembelajaran di Laboratorium Pusat

\begin{tabular}{|c|c|c|c|c|c|}
\hline \multirow[b]{2}{*}{ No } & \multirow[b]{2}{*}{ Media Pembelajaran } & \multicolumn{2}{|c|}{ Pengamatan } & \multirow[b]{2}{*}{ Jumlah } & \multirow[b]{2}{*}{ Keterangan } \\
\hline & & Ada & $\begin{array}{c}\text { Tidak } \\
\text { Ada }\end{array}$ & & \\
\hline 1 & Torso wanita & $\checkmark$ & & 1 buah & \\
\hline 2 & Torso laki laki & $\checkmark$ & & 1 buah & \\
\hline 3 & Torso ginjal manusia & $\checkmark$ & & 1 buah & \\
\hline 4 & Torso hewan & $\checkmark$ & & 1 buah & \\
\hline 5 & Kerangka manusia & $\checkmark$ & & 1 buah & \\
\hline 6 & Toro tubuh manusia & $\checkmark$ & & 1 buah & \\
\hline 7 & Torso pencernaan manusia & $\checkmark$ & & 1 buah & \\
\hline 8 & Torso telinga (indra pendengaran) & $\checkmark$ & & 1 buah & \\
\hline 9 & Torso kulit manusia & $\checkmark$ & & 1 buah & \\
\hline 10 & Torso indra penglihatan ( mata) & $\checkmark$ & & 1 buah & \\
\hline 11 & Torso kepala manusia & $\checkmark$ & & 1 buah & \\
\hline 12 & Torso hati manusia & $\checkmark$ & & 1 buah & \\
\hline
\end{tabular}

Berdasarkan hasil observasi tersebut di atas, maka dapat diketahui bahwa media pembelajaran yang terdapat di laboratorium pusat memadai, dalam kondisi baik, dan dapat membantu mahasiswa dalam proses perkuliahan.

Hasil observasi produk praktikum di laboratorium zoologi adalah hewan yang diawetkan (belalang, capung, kupu-kupu, kepik, dan serangga). Hasil observasi produk praktikum di laboratorium botani adalah herbarium tanaman herbal, herbarium jenis tanaman obat tradisional, herbarium daun tumbuhan yang dikeringkan, dan herbarium daun paku. Produk-produk tersebut diperoleh dari hasil praktikum mahasiswa dan dosen, serta dapat dijadikan sebagai bahan perkuliahan biologi. Menurut Rustaman (2003) laboratorium merupakan salah satu sarana penunjang yang banyak digunakan dalam proses belajar mengajar biologi, sedang sarana pada pembelajaran biologi dapat diartikan sebagai beberapa hal, seperti berikut : a). sebagai unsur pencapaian tujuan, artinya sarana bukan semata-mata sebagai alat bantu atau alat pelengkap, melainkan bersama-sama dengan materi dan metode berperan dalam proses kegiatan belajar 
mengajar, agar tujuan pembelajaran tercapai sesuai dengan yang telah dirumuskan; b). sebagai pengembang kemampuan, terutama alat-alat yang dapat dimanipulasi atau dirakit atau dimodifikasi atau media yang sengaja direncanakan untuk meningkatkan kemampuan tertentu, seperti kemampuan mengamati, menafsirkan, menyimpulkan, merakit alat, mengukur, memilih alat yang tepat; dan c) sebagai katalisator dalam pemahaman materi, misalnya melalui alat yang diperagakan, perbuatan, pengalaman langsung.

Dosen dan mahasiswa saling bekerja sama dalam pemanfaatan fasilitas, alat, bahan, media dan produk yang terdapat di laboratorium tersebut. Hal ini sangat membantu mahasiswa dalam perkuliahan, mahasiswa melakukan praktikum dan demonstrasi dengan disiplin dan tanggung jawab dalam memanfaatkan alat dan bahan agar tidak terjadi kerusakan terhadap alat maupun bahan tersebut. Kebaikan dari pelaksanaan praktikum antara lain: melibatkan mahasiswa secara langsung dalam mengamati suatu proses; mahasiswa dapat meyakini akan berhasilnya, karena langsung mendengar, melihat, meraba, dan mencium yang sedang dipelajari; mahasiswa akan mempunyai kemampuan dalam keterampilan mengelola alat, mengadakan percobaan, membuat kesimpulan, menulis laporan, dan mampu berfikir analisis; mahasiswa lebih cenderung tertarik pada obyek yang nyata di alam sekitarnya; memupuk dan mengembangkan sikap berfikir ilmiah, sikap inovatif, dan saling bekerja sama; membangkitkan minat ingin tahu, memperkaya pengalaman keterampilan kerja dan pengalaman berfikir ilmiah (Indarto, 2002).

Adapun jadwal perkuliahan di laboratorium pusat, zoologi dan botani dapat dilihat pada tabel berikut ini.

Tabel 5. Jadwal Perkuliahan pada Laboratorium Pusat

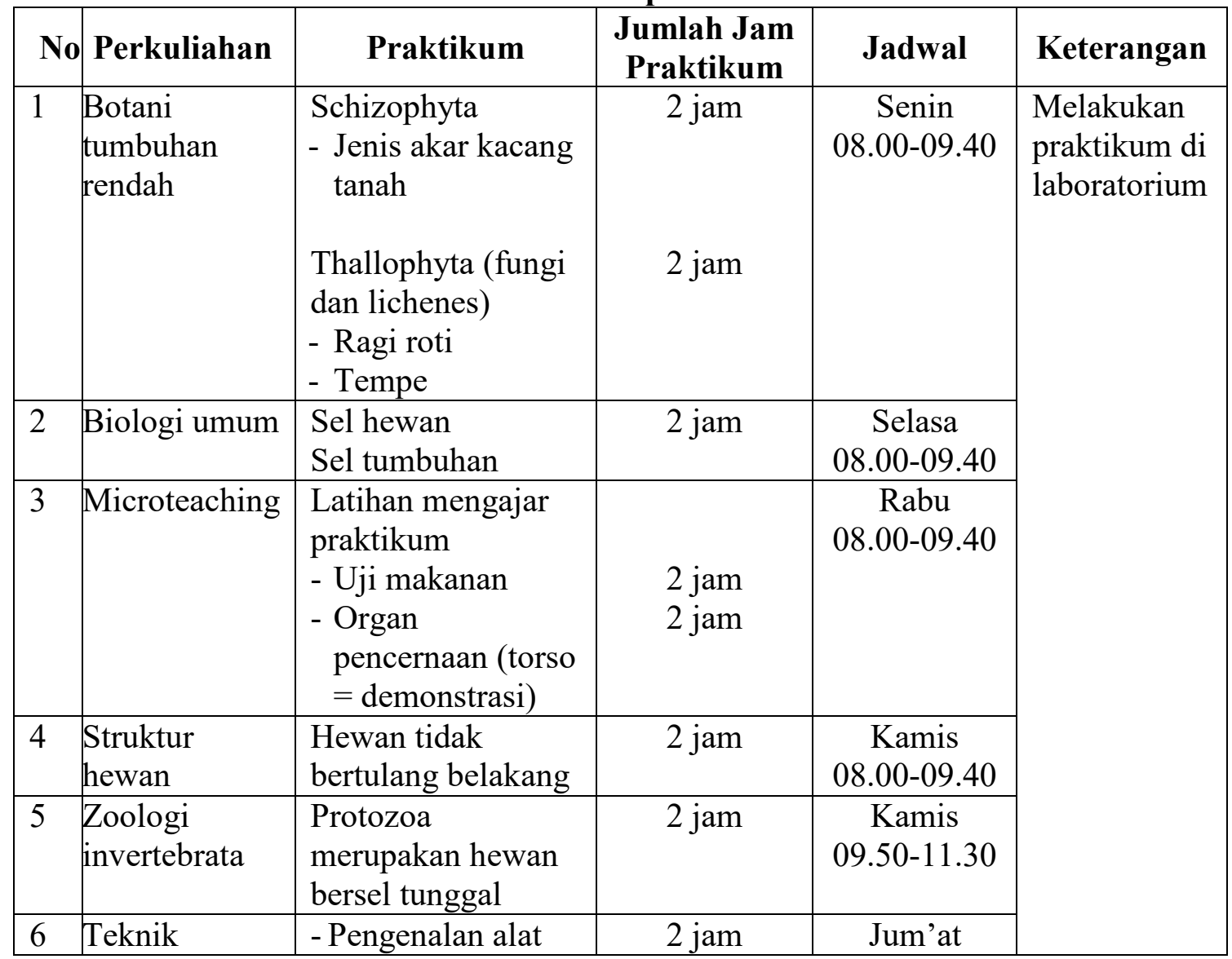




\begin{tabular}{|l|l|l|c|c|c|}
\hline & laboratorium & $\begin{array}{l}\text { dan bahan } \\
\text { laboratorium } \\
- \text { Cara kerja di } \\
\text { laboratorium }\end{array}$ & 2 jam & $08.00-09.40$ & \\
\hline 7 & $\begin{array}{l}\text { Media } \\
\text { pembelajaran } \\
\text { biologi }\end{array}$ & $\begin{array}{l}\text { - Torso tubuh } \\
\text { manusia } \\
- \text { Torso kerangka } \\
\text { manusia }\end{array}$ & 2 jam & Sabtu \\
\end{tabular}

Berdasarkan tabel 5. di atas, maka dapat diketahui bahwa jadwal perkuliahan di laboratorium pusat dilakukan selama dua jam untuk setiap mata kuliah yang diasuh oleh para dosen seperti botani tumbuhan rendah, biologi umum, microteaching, struktur hewan, zoologi invertebrata, teknik laboratorium, dan media pembelajaran biologi.

Tabel 6. Jadwal Perkuliahan di Laboratorium Zoologi

\begin{tabular}{|c|c|c|c|c|c|}
\hline No & Perkuliahan & Praktikum & $\begin{array}{c}\text { Jumlah } \\
\text { Jam } \\
\text { Praktikum } \\
\end{array}$ & Jadwal & Keterangan \\
\hline 1 & Entomologi & Serangga & 2 jam & $\begin{array}{c}\text { Senin } \\
08.00- \\
09.40\end{array}$ & \multirow[t]{5}{*}{$\begin{array}{l}\text { Melakukan } \\
\text { praktikum di } \\
\text { laboratorium }\end{array}$} \\
\hline 2 & Microteaching & $\begin{array}{l}\text { Latihan mengajar } \\
\text { praktikum } \\
\text { - Animalia } \\
\text { - Archeobakteria dan } \\
\text { eubakteria }\end{array}$ & $\begin{array}{l}2 \text { jam } \\
2 \text { jam }\end{array}$ & $\begin{array}{c}\text { Selasa } \\
08.00- \\
09.40\end{array}$ & \\
\hline 3 & $\begin{array}{l}\text { Teknik } \\
\text { laboratorium }\end{array}$ & $\begin{array}{l}\text { - Pengelolaan } \\
\text { laboratorium } \\
\text { - Keselamatan dan } \\
\text { keamanan } \\
\text { laboratorium }\end{array}$ & $\begin{array}{l}2 \text { jam } \\
2 \text { jam }\end{array}$ & $\begin{array}{c}\text { Rabu } \\
08.00- \\
09.40\end{array}$ & \\
\hline 4 & $\begin{array}{l}\text { Media } \\
\text { pembelajaran } \\
\text { biologi }\end{array}$ & $\begin{array}{l}\text { Hewan yang } \\
\text { diawetkan (belalang, } \\
\text { capung, kupu-kupu, } \\
\text { kepik, dan serangga) }\end{array}$ & 2 jam & $\begin{array}{c}\text { Kamis } \\
08.00- \\
09.40\end{array}$ & \\
\hline 5 & $\begin{array}{l}\text { Zoologi } \\
\text { vertebrata }\end{array}$ & $\begin{array}{l}\text { - Pisces } \\
\text { - Amphibi } \\
\text { - Reptil } \\
\text { - Aves } \\
\text { - Mamalia }\end{array}$ & $\begin{array}{l}2 \text { jam } \\
2 \text { jam } \\
2 \text { jam } \\
2 \text { jam } \\
2 \text { jam }\end{array}$ & $\begin{array}{c}\text { Jum'at } \\
08.00- \\
09.40\end{array}$ & \\
\hline
\end{tabular}

Pemanfaatan laboratorium zoologi adalah untuk praktikum perkuliahan entomologi, microteaching, teknik laboratorium, media pembelajaran biologi, dan zoologi vertebrata.

Tabel 7. Jadwal Perkuliahan di Laboratorium Botani

\begin{tabular}{|l|l|l|c|c|l|}
\hline No & \multirow{2}{*}{ Perkuliahan } & \multicolumn{1}{|c|}{ Praktikum } & $\begin{array}{c}\text { Jumlah } \\
\text { Jam } \\
\text { Praktikum }\end{array}$ & Jadwal & Keterangan \\
\hline 1 & Botani tingkat & - Bryophyta & 2 jam & Senin & Melakukan \\
& tinggi & - Pteridophyta & $2 \mathrm{jam}$ & $08.00-$ & praktikum di \\
& & - Spermatophyta & $2 \mathrm{jam}$ & 09.40 & laboratorium \\
\hline
\end{tabular}




\begin{tabular}{|c|c|c|c|c|}
\hline 2 & $\begin{array}{l}\text { Fisiologi } \\
\text { tumbuhan }\end{array}$ & $\begin{array}{l}\text { - Fotosintesis } \\
\text { - Respirasi tumbuhan }\end{array}$ & $\begin{array}{l}2 \text { jam } \\
2 \text { jam }\end{array}$ & $\begin{array}{c}\text { Selasa } \\
08.00- \\
09.40\end{array}$ \\
\hline 3 & Microteaching & $\begin{array}{l}\text { Latihan mengajar } \\
\text { praktikum } \\
\text { - Pertumbuhan dan } \\
\text { perkembangan } \\
\text { tumbuhan } \\
\text { - Plantae }\end{array}$ & $\begin{array}{l}2 \text { jam } \\
2 \text { jam }\end{array}$ & $\begin{array}{c}\text { Rabu } \\
08.00- \\
09.40\end{array}$ \\
\hline 4 & $\begin{array}{l}\text { Teknik } \\
\text { Laboratorium }\end{array}$ & $\begin{array}{l}\text { - Mikroskop } \\
\text { - Respirometer } \\
\text { Ganong's dan } \\
\text { audust }\end{array}$ & $\begin{array}{l}2 \text { jam } \\
2 \text { jam }\end{array}$ & $\begin{array}{c}\text { Kamis } \\
08.00- \\
09.40\end{array}$ \\
\hline 5 & $\begin{array}{l}\text { Media } \\
\text { pembelajaran } \\
\text { biologi }\end{array}$ & $\begin{array}{l}\text { Herbarium tanaman } \\
\text { herbal, herbarium } \\
\text { jenis tanaman obat } \\
\text { tradisional, } \\
\text { herbarium daun } \\
\text { tumbuhan yang } \\
\text { dikeringkan, dan } \\
\text { herbarium daun paku. }\end{array}$ & 2 jam & $\begin{array}{c}\text { Jum'at } \\
08.00- \\
09.40\end{array}$ \\
\hline
\end{tabular}

Pemanfaatan laboratorium botani adalah untuk praktikum perkuliahan botani tingkat tinggi, fisiologi tumbuhan, microteaching, teknik laboratorium, dan media pembelajaran biologi.

Pemanfaatan laboratorium pusat, zoologi dan botani ini memberikan dampak positif yang sangat signifikan kepada mahasiswa. Mereka dapat memperoleh ilmu secara langsung berdasarkan pengamatan yang dilakukan. Menurut Sukarso (2005: 83), secara garis besar fungsi laboratorium dalam proses pendidikan adalah sebagai berikut: 1) Sebagai tempat untuk berlatih mengembangkan keterampilan intelektual melalui kegiatan pengamatan, pencatatan dan pengkaji gejala-gejala alam; 2) Mengembangkan keterampilan motorik mahasiswa. Mahasiswa akan bertambah keterampilannya dalam mempergunakan alat-alat media yang tersedia untuk mencari dan menemukan kebenaran; 3) Memberikan dan memupuk keberanian untuk mencari hakekat kebenaran ilmiah dari sesuatu objek dalam lingkungn alam dan sosial; 4) Memupuk rasa ingin tahu mahasiswa sebagai modal sikap ilmiah seseorang calon ilmuan; dan 5) Membina rasa percaya diri sebagai akibat keterampilan dan pengetahuan atau penemuan yang diperolehnya.

Petugas laboratorium menjalankan tugasnya sebagai petugas lab dengan baik. Petugas lab bertangung jawab terhadap kenyamanan laboratorium. Petugas lab juga harus memastikan bahwa alat-alat dan bahan yang telah digunakan oleh mahasiswa setelah melakukan praktikum dalam keadaan bersih dan tersusun kembali dengan rapi. Pengelolaan laboratorium juga penting untuk diperhatikan yang secara garis besar menurut Rustaman, dkk (2003) pengelolaan laboratorium dibedakan menjadi kegiatan dalam pemeliharaan, penyediaan, dan peningkatan daya guna laboratorium.

Hasil wawancara terhadap dosen, petugas lab dan mahasiswa menunjukkan bahwa pemanfaatan laboratorium pusat, botani dan zoologi pada perkuliahan biologi telah berjalan dengan baik. Engkoswara (2009: 34) mengatakan bahwa melalui kegiatan praktikum yang biasanya dilakukan di laboratorium, mahasiswa diharapkan 
dapat: mengembangkan berbagai keterampilan secara terintegrasi, mengenal berbagai peralatan laboratorium, mengenal berbagai desain dan peralatan untuk eksperimen, mengembangkan keterampilan dalam mengumpulkan dan menginterprestasikan data, mengembangkan sikap untuk melakukan sesuatu secara tepat dan akurat, mengembangkan keterampilan dalam mengobservasi, mengembangkan kemampuan dalam mengkomunikasikan hasil eksperimen, mengembangkan kecakapan dalam menulis laporan, mengembangkan kemampuan untuk belajar dan melakukan percobaan sendiri, menambah keberanian berfikir sendiri dan menanggung resiko, merangsang berfikir mahasiswa melalui eksperimen, mengembangkan keterampilan dalam memecahkan masalah dengan berbagai, dan variabel yang banyak dan berbagai kemungkinan pemecahannya.

Kendala di laboratorium pusat, zoologi, botani adalah kekurangan alat dan bahan tertentu, pemeliharaan alat dan bahan yang masih kurang, bahkan sangat diperlukan servis perbaikan pada mikroskop yang telah banyak berjamur dan lensanya kurang bersih. Kegiatan mahasiswa yang tidak tertib dan disiplin menjadi permasalahan yang sering muncul saat praktikum. Indarto (2002) menjelaskan bahwa kelemahan/ kekurangan dari praktikum antara lain: dosen harus benar-benar mampu, menguasai materi dan ketrampilan; tidak semua mata kuliah dapat dipraktekkan dan tidak semua diajarkan dengan metode praktikum; alat-alat dan bahan yang mahal harganya dapat menghambat untuk melakukan praktik; dan banyak waktu yang diperlukan untuk praktikum, sehingga kemungkinan dapat dilaksanakan diluar jam pelajaran.

\section{KESIMPULAN}

Pemanfaatan laboratorium pusat, zoologi, dan botani dalam perkuliahan Biologi telah berjalan dengan baik. Dosen, petugas lab dan mahasiswa saling bekerja sama dalam pemanfaatan alat, bahan, media dan produk yang terdapat di laboratorium tersebut.

Kendala yang dihadapi oleh dosen dan mahasiswa terhadap pemanfaatan laboratorium pusat, zoologi, dan botani dalam perkuliahan Biologi adalah kedisiplinan dan tanggung jawab dalam memanfaatkan peralatan maupun bahan, sehingga terjadi kerusakan terhadap alat maupun bahan tersebut; kekurangan alat dan bahan tertentu; pemeliharaan alat dan bahan yang masih kurang, bahkan sangat diperlukan servis perbaikan pada mikroskop yang telah banyak berjamur dan lensanya kurang bersih.

\section{DAFTAR PUSTAKA}

Anonim. (2007). Interaksi dan Motivasi Belajar Mengajar. Jakarta: Raja Grafindo Persada.

Creswell, J.W. (2013). Educational Research: Planning, Conducting, and Evaluating Quantitative and Qualitative Research. Third Edition. New Jersey: Pearson Education,

Inc.

Engkoswara. (2009). Nilai Suatu Praktikum dalam Laboratorium. Jakarta: Rineka Cipta

Indarto. (2002). Metodelogi Penelitian. Jakarta: Rineka Cipta

Rustaman. (2003). Proses Belajar dalam Praktik di laboratorium. Jakarta: Bumi Aksara.

Sukarso. (2005). Penelitian di Laboratorim. Jakarta: Pustaka Ilmu.

Wirjosoemarto, K. dkk., (2013). Teknik Laboratorium, Bandung: FPMIPA UPI. 